УДК 930

\title{
КУЛЬТУРНО-ХРОНОЛОГИЧЕСКИЕ КОМПЛЕКСЫ БЕРЁЗОВОГРИВСКО-АЛЕКСЕЕВСКОГО ІІІ ПОСЕЛЕНИЯ В НИЖНЕМ ПРИКАМЬЕ
}

\author{
(c) 2021 А.В. Шипилов
}

Институт археологии им. А.Х. Халикова Академии наук Республики Татарстан. г. Казань.

Статья поступила в редакцию 25.09.2021

\begin{abstract}
В статье публикуются материалы исследований Берёзовогривско-Алексеевского III поселения, расположенного в Нижнем Прикамье. Наиболее ранние находки данного поселения связаны с камской неолитической культурой. Несколько более позднюю хронологическую позицию занимают комплексы носителей ямочно-гребенчатой, русско-азибейской и новоильинской керамики. Отдельного внимания в статье заслуживает комплекс находок, связанный с гаринской энеолитической культурой. Наибольшее количество находок относится к эпохе бронзы. Они объединены в несколько комплексов, имеющих принадлежность к срубной, луговской, маклашеевской культурам. Позднейшая история Берёзовогривско-Алексеевского III поселения связана с ананьинской культурно-исторической областью.

Ключевые слова: керамика, неолит, энеолит, эпоха бронзы, ранний железный век, Нижнее Прикамье.
\end{abstract}

DOI: $10.37313 / 2658-4816-2021-3-4-102-114$

Берёзовогривско-Алексеевское III поселение располагается в 3,2 км к северо-западу от р.ц. Алексеевский. В различные годы на поселении проводились неоднократные изыскания ${ }^{12}$. К сожалению, полученные материалы не были обобщены. Целью данной работы является обобщение и введение в научный оборот источникового материала, полученного в ходе исследований Берёзовогривско-Алексеевского III поселения.

В результате проведенных археологических изысканий был получен богатый и выразительный массив находок, судя по которому можно выделить несколько этапов заселения территории площадки рассматриваемого поселения.

Первый этап заселения Берёзовогривско-Алексеевского III поселения, вероятно, относится к эпохе неолита, его маркируют фрагменты керамики камской неолитической культуры. Это фрагменты толстостенной лепной посуды с примесью песка и шамота в формовочной массе (Рис.1: 1-5).

$\overline{\text { Антон Валентинович Шипилов, кандидат истори- }}$ ческих наук, старший научный сотрудник

E-mail: Shipilov_anton@mail.ru
В орнаментации сосудов применялся преимущественно длинный мелкозубчатый гребенчатый штамп. Эпизодическое его применение сочеталось с применением короткого линзовидного гребенчатого штампа (рис.1:3). Единично в орнаментации керамики камской культуры Берёзовогривско-Алексеевского III поселения присутствуют ямки под срезом венчика (Рис. 1: 1). Орнаментальные мотивы представлены в виде поясов из вертикально расположенных оттисков длинного мелкозубчатого гребенчатого штампа (Рис. 1:1-3, 5), вертикального зигзага (рис.1:4). На одном из венчиков присутствует пояс из оттисков короткого линзовидного штампа, расположенного под наклоном (Рис.1:3). Толщина стенок сосудов варьируется от 0,6 до 1 см. Аналогии данной группе керамики прослеживаются в материалах Мурзихинской IV (9, рис. $4: 1,6)$ и Балахчинской VIa (4, рис. $3: 1)$ стоянок.

Немногочисленные фрагменты лепной ямочно-гребенчатой керамики (Рис.1: 6-8), обнаруженные на Берёзовогривско-Алексеевского III поселении, вероятно, также следует отнести к первому этапу функцио- 
нирования рассматриваемого объекта. Она занимает синхронные позиции с керамикой камской культуры (4, с. 243, 245-246). Вся ямочно-гребенчатая керамика толстостенна, ее толщина не превышает 0,8 см. В формовочной массе присутствует песок и шамот. По всей внешней поверхности присутствует орнаментация, выполненная оттисками короткого и длинного мелкозубчатых гребенчатых штампов. В единственном экземпляре присутствует фрагмент, на котором орнаментация выполнена крупнозубчатым гребенчатым штампом. Разделителями орнаментальных зон на керамике выступают пояса из круглых конических ямок. Среди орнаментальных композиций присутствует вертикальный зигзаг (Рис.1: 7), пояса из оттисков короткого линзовидного штампа, расположенного под наклоном (Рис.1:8). Аналогичная керамика присутствует на Удельно - Шумецкой V стоянке, Дубовском VIII, Дубовском XXII, Отарском $\mathrm{VI}^{11}$ поселениях.

Присутствие на поселении ямочно-гребенчатой керамики, вероятно, следует рассматривать как отражение культурных контактов ее носителей с населением Нижнего Прикамья в эпоху неолита.

Со вторым этапом функционирования поселения, вероятно, следует связать немногочисленные фрагменты керамики русско-азибейского типа (Рис. 2: 1-2). По всей внешней поверхности этой керамики присутствует орнаментация, выполненная короткими гребенчатыми штампами. Дополнительными элементами орнаментации выступают круглые ямочные вдавления, расположенные под воротничковым оформлением венчика. Судя по фрагментам сосуды имели прикрытую профилировку. Толщина керамики составляет 0,7-0,9 см, в формовочной массе которой присутствует обильная примесь песка и шамота.

Присутствие на Берёзовогривско-Алексеевском III поселении керамики новоильинской культуры (Рис.2: 3-7) со всей очевидностью иллюстрирует третий этап его функционирования. Судя по фрагментам посуда имела прикрытую профилировку. В составе формовочной массы сосудов присутствует песок и шамот. По всей поверхности посуды новоильинской культуры присутствует орнаментация, выполненная различными ногтевидными вдавлениями, насечками и короткими мелкозубчатыми гребенчатыми штампами (Рис.2: 3-7). Орнаментальные композиции состоят из горизонтальных поясов из вышеотмеченных элементов орнаментации. Аналогии новоильинской керамики Берёзовогривско-Алексеевского III поселения прослеживаются с керамикой, обнаруженной на Новоильинском III поселении в Среднем Прикамье 2 .

Эпоху позднего энеолита на поселении маркируют немногочисленные фрагменты посуды гаринской культуры (Рис.3). Керамика данной культуры лепная, в составе формовочной массы присутствует примесь органики. По всей внешней поверхности керамика гаринской культуры Берёзовогривско-Алексеевского III поселения орнаментирована. Орнаментальные композиции состоят из горизонтальных поясов, выполненных оттисками короткого овального гребенчатого штампа, расположенного вертикально или под наклоном. Близкая по формально-типологическим признакам керамика была обнаружена на поселении Бор V, а также на поселении Большая Ока I ${ }^{1}$.

C носителями гаринских культурных традиций, возможно, следует связывать и весьма выразительный массив каменных изделий, обнаруженных на поселении, аналогии которым прослеживаются на поселенческих памятниках гаринской культуры.

Весьма ярким и выразительным представляется набор орудий охоты, в котором присутствуют наконечники стрел (Рис. 6: 1-3) и дротиков (Рис.6:4, 7, 8). Как правило, они изготовлены из отщепов и плитчатого кремня. Наконечники стрел обладают листовидной формой и имеют линзовидное сечение. Их длина составляет от 2 до 4 см при ширине пера 0,8-0,9 см. У двух орудий прослеживается намеченный черешок (Рис.6:1,2). Обнаруженные на Берёзово- 
гривско-Алексеевском III поселении наконечники стрел находят аналогии среди находок поселения гаринской культуры Бор I ${ }^{1}$.

Не меньшего внимания заслуживают наконечники дротиков (Рис.6: 4, 7, 8). Они обладают также листовидной формой, от наконечников стрел они отличаются большими параметрами. Их длина составляет от 5 до 6,5 см при ширине пера от 2 до 3 см. На одном из наконечников присутствует черешок (Рис. 6:4). Сходство с этими находками прослеживается на поселении гаринской культуры Бор IV (1, рис. 18:15).

Помимо орудий охоты в массиве каменных орудий Берёзовогривско-Алексеевского III поселения присутствуют орудия скобле-режущего назначения - это скребки, ножи (Рис. 6: 5, 6, 9, 10; 7: 1-3).

Скребки (Рис.7:1-3) изготовлялись, как правило, на кремневых отщепах серого цвета. Наиболее близкие по форме орудия были прослежены в материалах поселения гаринской культуры Бор I ${ }^{1}$.

Среди ножей Берёзовогривско-Алексеевского III поселения примечательна находка саблевидной формы, изготовленная из двухцветного кремневого отщепа (Рис. 6: 6). Аналогии данному ножу усматриваются в материалах Астраханцевского поселения, имеющего принадлежность к гаринской культуре (21, рис. 35:14). С вышеотмеченным ножом сближается другое орудие с рассматриваемого поселения, но оно изготовлено из более массивного кварцитового отщепа серого цвета и обладает более широким лезвием (Рис.6:10). Аналогичные по форме ножей были получены при исследовании поселения гаринской культуры Бор $\mathrm{I}^{1}$. Оригинальностью отличается еще одно орудие, изготовленное на двухцветном кремневом отщепе, которое обладает ланцетовидной формой (Рис. 6: 5).

Среди ножей Берёзовогривско-Алексеевского III поселения одно орудие изготовлено на крупной ножевидной пластине белого опочного кремня (Рис. 6:9). По своей форме орудие можно отнести к категории прямолезвиных с горбатой спинкой. Лез- вие ножа оформлено краевой ретушью. Его длина составила 10 см при ширине лезвия 2,5 см. Аналоги данному ножу прослеживаются в материалах поселения гаринской культуры Бор $\mathrm{V}^{1}$.

Одним экземпляром представлена проколка, изготовленная на ножевидной пластине с серединным жалом и прямыми плечиками (Рис. 7: 4). Длина орудия составила 4,7 см при ширине 1,5 см. Данное орудие, вероятно, использовалось для работы с мягкими материалами, в том числе при обработке шкур.

Категорию каменных орудий Берёзовогривско-Алексеевского III поселения, которые вполне можно связать с деревообработкой, составляют кремневые тесла, долота и один перфоратор.

Тесла (Рис. 6: 5, 6) представлены двумя экземплярами. По всей поверхности орудия отшлифованы, обладают подтрапециевидными очертаниями и клиновидным сечением. Они отличаются небольшими параметрами, их длина не превышает 5 см при ширине рабочей части 2,7 см. Аналогичные орудия присутствуют в материалах поселения гаринской культуры Бор I ${ }^{1}$.

Долота на рассматриваемом поселении также представлены двумя экземплярами. В отличие от тесел, имеющиеся долота отличаются более крупными параметрическими данными. Длина орудий не превышает 9,5 см. при ширине рабочей части 3 см. Сходство с данными орудиями прослеживается в материалах поселения гаринской культуры Бор $\mathrm{V}^{1}$.

Одно орудие следует интерпретировать как перфоратор (рис.7:7). Оно изготовлено на ножевидной пластине, обладает подтреугольными очертаниями и трехгранным сечением. Длинна орудия при ширине лезвия 2 см составляет 7, 5 см. Аналог данному орудию прослеживается в материалах поселения гаринской культуры Бор V ${ }^{1}$.

Следующий этап функционирования Берёзовогривско-Алексеевского III поселения относится к эпохе поздней бронзы, где наиболее ранние находки этой поры 
имеют принадлежность к срубной культуре. Керамика срубной КИО, обнаруженная на Берёзовогривско-Алексеевском III поселении, характеризуется банковидной профилировкой. Поверхность посуды небрежно заглажена. В качестве основной примеси в глиняном тесте использовался шамот. Основными способами нанесения орнаментации были оттиски гладкого линзовидного и подтреугольного штампов (Рис.4:1-2). Подобная керамика широко известна на памятниках срубной КИО Нижнего Прикамья и Среднего Поволжья. Подобная керамика присутствует в материалах Курманаковской IV стоянки ${ }^{10}$.

Весьма любопытно присутствие в массиве находок эпохи поздней бронзы фрагмента сосуда банковидной формы (Рис.4:3), по внешней стороне которого присутствуют оттиски крупного шнура. Аналогичная посуда была обнаружена в массиве находок Коминтерновского II кургана, а также Курманаковской IV стоянки. Характер орнаментации керамики по своим формально-типологическим признакам позволяет связать ее с поздняковскими древностями и поместить в хронологические рамки XVIII-XVдо н.э. ${ }^{15}$.

Весьма представителен синхронный с поздняковской керамикой массив керамики луговской культуры. Он представлен фрагментами посуды (Рис.4:4-5) с хорошо заглаженной поверхностью. Основными примесями в глиняном тесте луговской керамики была раковина и органика. Преимущественно на внешней ее поверхности присутствует орнаментация. Орнамент наносился, как правило, оттисками сплошного штампа, реже гладкого и разреженного штампов. Орнаментация представлена простыми композициями, такими как горизонтальный зигзаг, наклонные и горизонтальные линии.

Судя по венчикам (Рис. 4: 4-5) сосуды имели горшковидную форму. Ближайшие аналогии луговской керамике Берёзовогривско-Алексеевского III поселения прослеживаются в материалах археологических памятников Нижнего Прикамья: Рысовского III поселения ${ }^{17}$, Дубовогривской $\mathrm{II}^{16}$, Луговской $\mathrm{I}^{6}$ стоянок, а также на могильнике Такталачук ${ }^{7}$.

Луговской тип керамики был выделен и впервые описан А.В. Збруевой [5, с. 204] после раскопок группы стоянок у п. Луговой. В настоящее время керамику данного культурного образования следует помещать в хронологические рамки XV-XIV вв. до н.э. ${ }^{8}$

Дальнейший этап заселения стоянки соотносится с носителями посуды атабаевского этапа маклашеевской культуры (Рис.4: 6-10). Атабаевская керамика, выявленная на стоянке, пористая, желто-оранжевого цвета, с примесью раковины. Толщина стенок фрагментов этой керамики составляет 0,5-0,7 см. В большинстве случаев венчик сосуда с внешней стороны украшен характерным валиком - приостренным (Рис.4: 6, 8-10) или сглаженным (Рис. 4: 7). Внешняя поверхность сосудов гладкая, заглаженная, орнамент размещался на горловине и верхней трети тулова сосуда.

В орнаментации керамики данной группы преобладают оттиски гребенчатого и гладкого штампа. Основной орнаментальной композицией являются горизонтальные линии и зигзаг, а также пояски ямок и овальных вдавлений. Близкие по формально-типологическим признакам сосуды были получены при исследовании Игимской, а также Каетубинской островной стоянок 20 .

Общая дата атабаевского этапа маклашеевской культуры в Нижнем Прикамье относится к рубежу XIV/XIII - XII вв. до н.э. ${ }^{13},{ }^{9}$. Вероятно, в этих же рамках датируется керамика атабевского этапа маклашеевской культуры обнаруженная на Берёзовогривско-Алексеевском III поселении.

Наличие в массиве находок Берёзовогривско-Алексеевском III поселения незначительного количества маклашеевской керамики (Рис.5: 3-4) свидетельствует о продолжении бытования поселения вплоть до конца бронзового века.

Это керамика серого и оранжевого цвета с примесью раковины в глине. Внешняя по- 
верхность сосудов гладкая, орнамент размещался преимущественно на горловине и в верхней части сосуда (Рис. 5: 3-4). Характерной особенностью этой керамики является группировка ямок и наличие плоского воротничка. Близкая по облику керамика маклашеевской культуры была обнаружена в ходе исследований и Игимской стоянки (раскоп II) ${ }^{20}$.

Датировка маклашеевского керамического комплекса Игимской стоянки определяется по общей дате существования маклашеевского этапа маклашеевской культуры в пределах XII/XI - 1 пол. IX в. до н.э..

Функционирование БерёзовогривскоАлексеевского III поселения в финале эпохи, бронзы подтверждается присутствием на поселении единичнго фрагмента керамики имеющего принадлежность к культуре текстильной керамики (Рис.5:2).

Заключительный этап функционирования стоянки, вероятно, связан с ранним железным веком, который иллюстрирует также единственный фрагмент сосуда, имеющий принадлежность к населению ананьинской КИО (Рис.5: 5), датировку которого, вероятно, следует помещать в хронологические рамки IX - III вв. до н.э. ${ }^{14}$.

\section{ПРИМЕЧАНИЯ}

${ }^{1}$ Бадер О.Н. Поселения Турбинского типа в Среднем Прикамье // МИА №99. М,, 1961. -198 с.

${ }^{2}$ Бадер О.Н. Третье Ново-Ильинское поселение // Отчёты Камской (Воткинской) археологической экспедиции. Вып. 2. 1961. С. 22-28.

${ }^{3}$ Выборнов А.А. Неолит Волго - Камья. Самара, 2008. - 490 c.

${ }^{4}$ Выборнов А.А., Шипилов А.В. Неолитический комплекс Балахчинской VI А стоянки в приустьевом Прикамье // ПА №1.2019. С. 47-58.

${ }^{5}$ Збруева А.В. История населения Прикамья в ананьинскую эпоху // МИА №30. М.,1952. - 319 с.

${ }^{6}$ Збруева А.В. Памятники эпохи поздней бронзы в Приказанском Поволжье и Нижнем Прикамье // МИА №80. М., 1960. С. 10-95.

${ }^{7}$ Казаков Е.П. Погребения эпохи бронзы могильника Такталачук // Древности Икско-Бельского междуречья. Казань, 1978. С. 67-108.

${ }^{8}$ Колев Ю.И. Заключительный этап эпохи бронзы в Поволжье // История Самарского Поволжья с древнейших времён до наших дней. Бронзовый век. Самара, 2000. -336с.

${ }^{9}$ Кузьминых С. В., Чижевский А. А. Ананьинский мир: взгляд на современное состояние проблемы // У истоков археологии Волго-Камья (150 - летию открытия Ананьинского могильника) / Археология Евразийских степей. Вып.8. Елабуга, 2009. С. 29-55.

10 Лыганов А.В. Культурно-хронологические комплексы Курманаковской IV стоянки в Нижнем течении реки Мёша // AEC №2.2021. С. 29-46.

${ }^{11}$ Никитин B.B. Культура носителей посуды с гребенчато-ямочным орнаментом в марийско-казанском Поволжье. Йошкар-Ола, 2015. - 361с.

${ }^{12}$ Свод памятников археологии Республики Татарстан. Том.3. Казань, 2007. - 526 с.

${ }_{13}$ Чижевский А.А. Финал бронзового века на территории Нижнего Прикамья: некоторые аспекты проблемы. // XVII Уральское археологическое совещание: МНК (Екатеринбург, 19-22 ноября 2007 г.). Екатеринбург; Сургут, 2007. С. 174-176.

14 Чижевский А. А., Антипина Е. Е., Асылгараева Г. Ш., Нуретдинова А. Р. Коллекция раннего железного века из собрания археологического музея Казанского (Приволжского) Федерального Университета // ПА №3. 2018. С. 68-87).

15 Чижевский А.А., Губин А. С., Лыганов А. В. Коминтерновский курган №2. //Урало-Поволжье в древности и средневековье. Материалы международной научной конференции $\mathrm{V}$ Халиковские чтения. Казань, 2011. С. 261-271.

16 Чижевский А.А., Лыганов А.В., Морозов В.В. Исследование памятников археологии на острове Дубовая грива в 2009-2010 г. // ПА №1.2012. С. 94-115.

17 Чижевский А.А., Лыганов А.В., Шипилов А.В. Рысовский археологический комплекс // Актуальные вопросы российской археологии. Вып.1. Казань, 2014. С. 23-53.

18 Чижевский А.А., Шипилов А.В., Капленко Н.М. Итоги исследования Каентубинской островной стоянки в 2004 году // ПА №1.2017. С. 50-70.

${ }^{19}$ Шипилов А.В. Культурно-хронологические комплексы Мурзихинской IV стоянки в Нижнем Прикамье // ПА №2.2015. С. 313-325.

${ }^{20}$ Шипилов А.В. Материалы эпохи поздней бронзы и раннего железа Игимской стоянки (Нижнее Прикамье) // AEC №3.2017. С. 111-119.

${ }^{21}$ Шорин А.Ф. Энеолит Урала и сопредельных территорий: проблемы культурогенеза. Екатеринбург, 1999. -181с. 

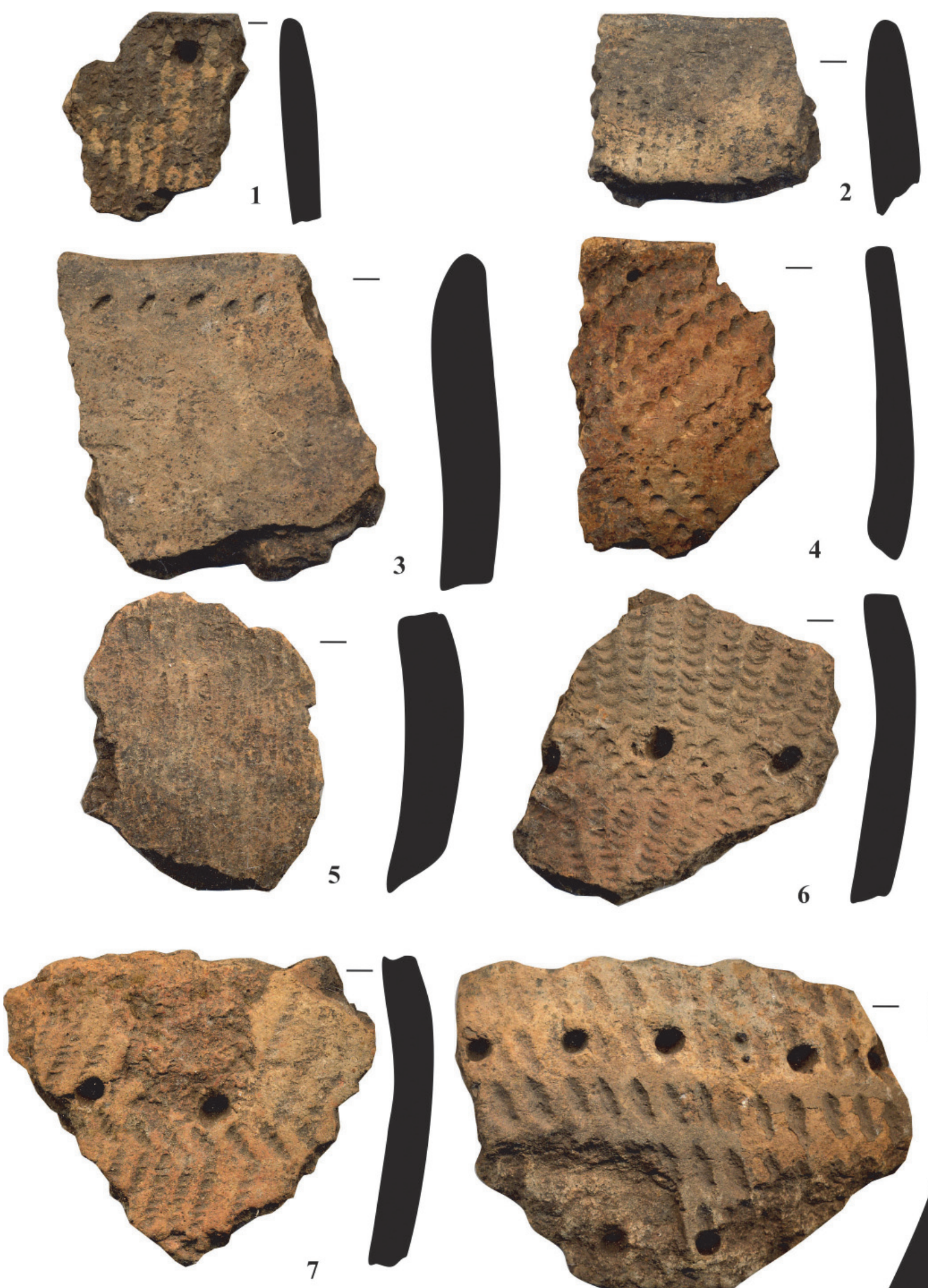

Рис.1

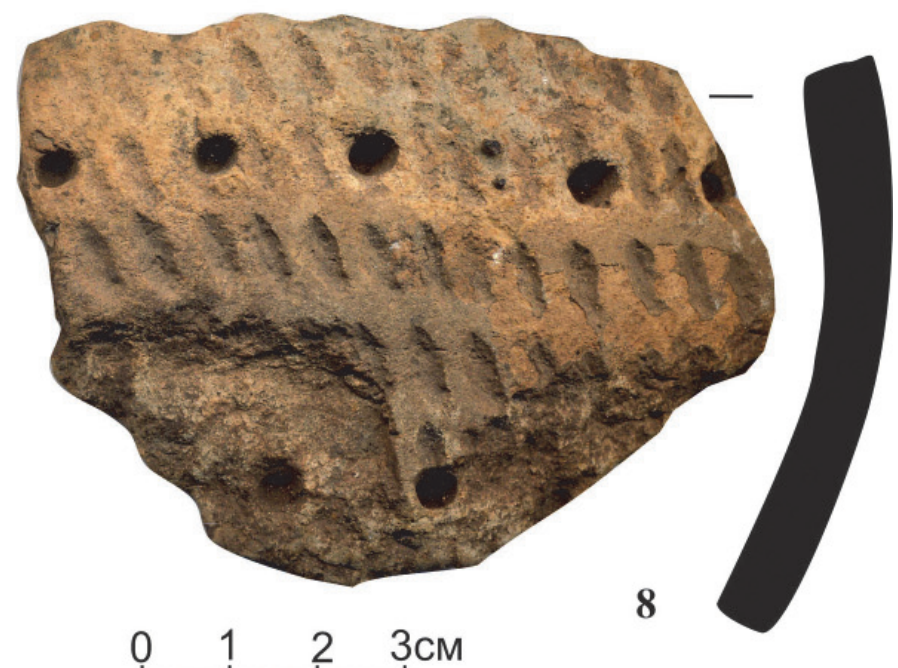



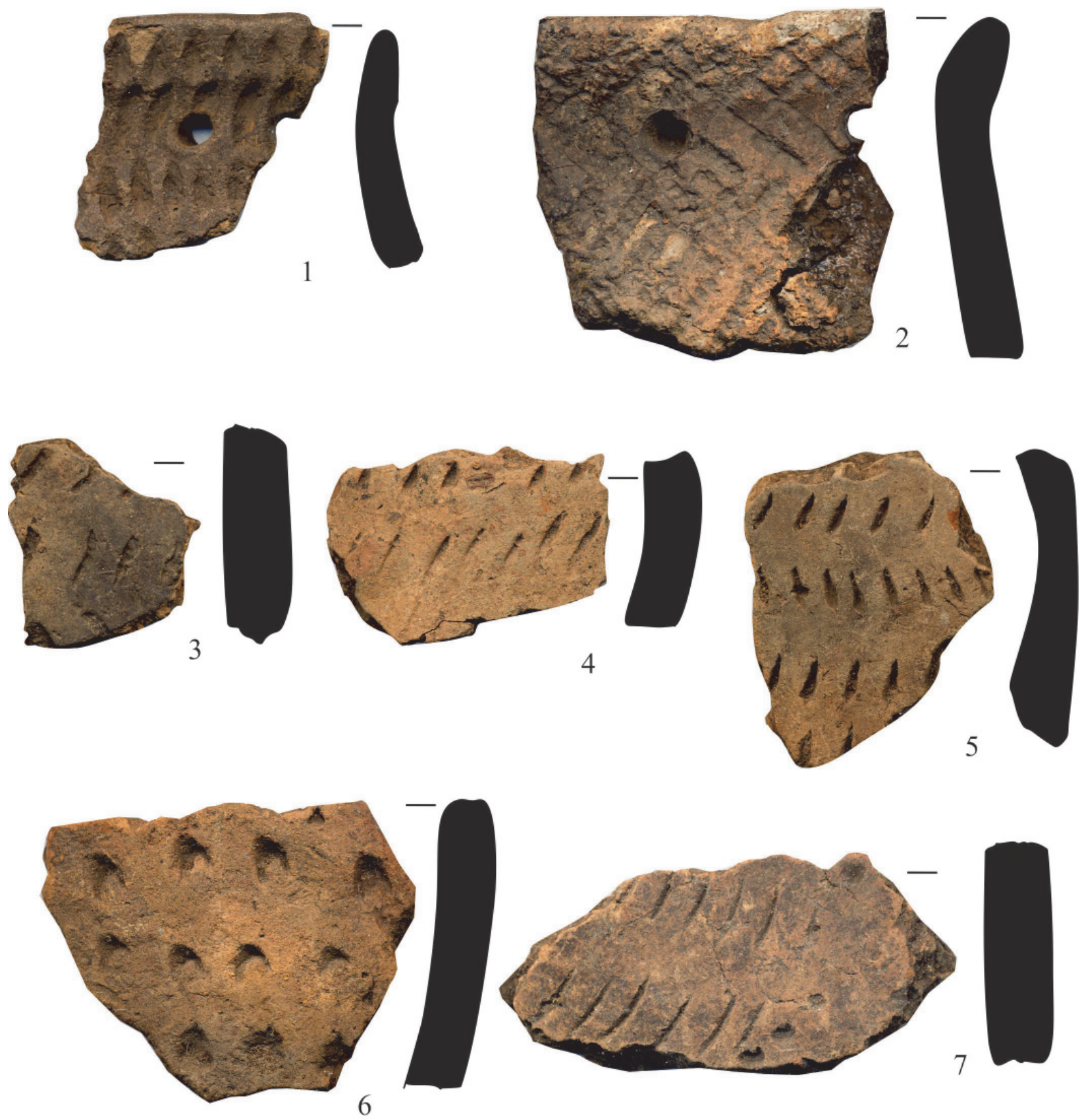

Рис.2

$0 \quad 123 \mathrm{~cm}$



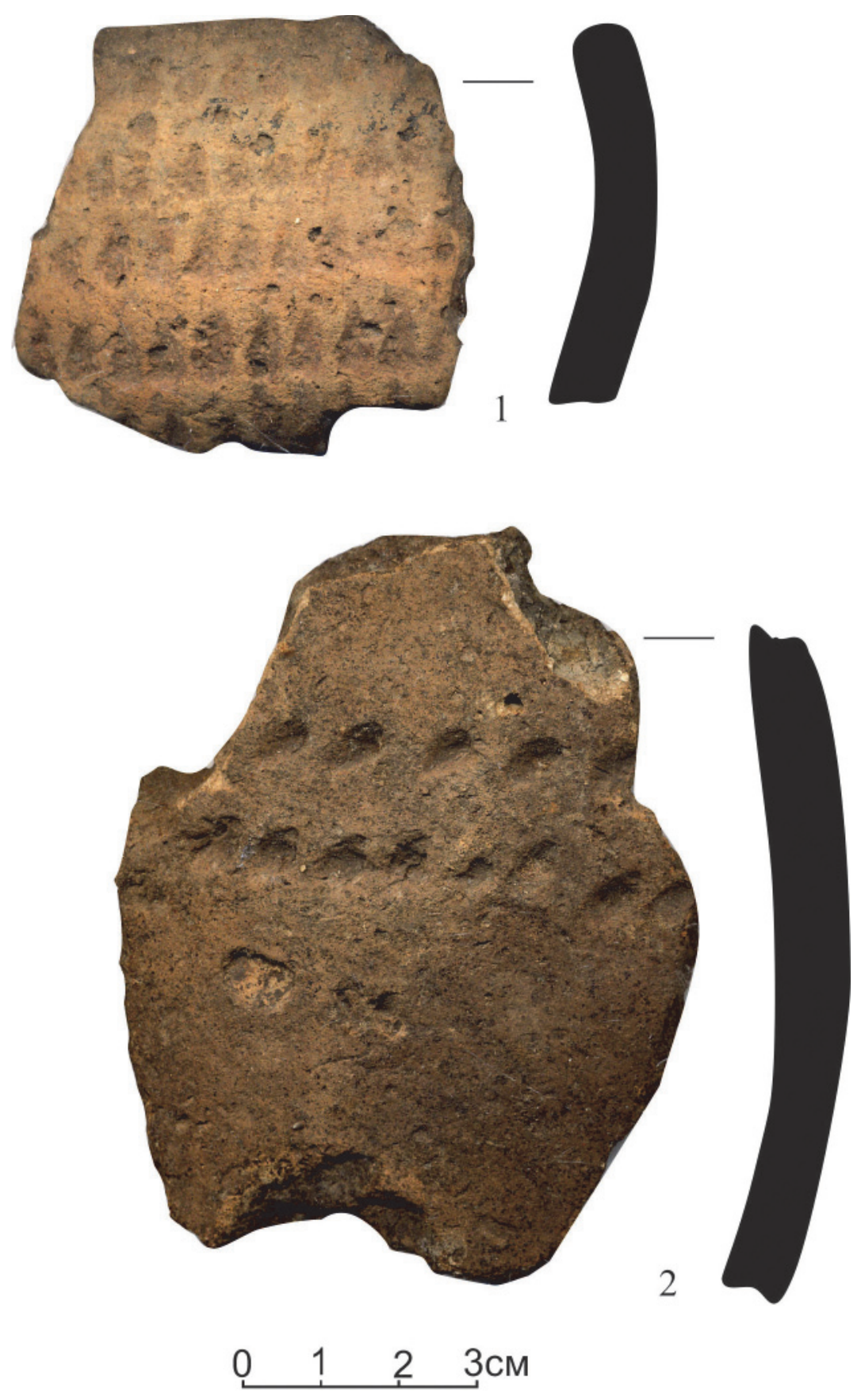

Рис.3 

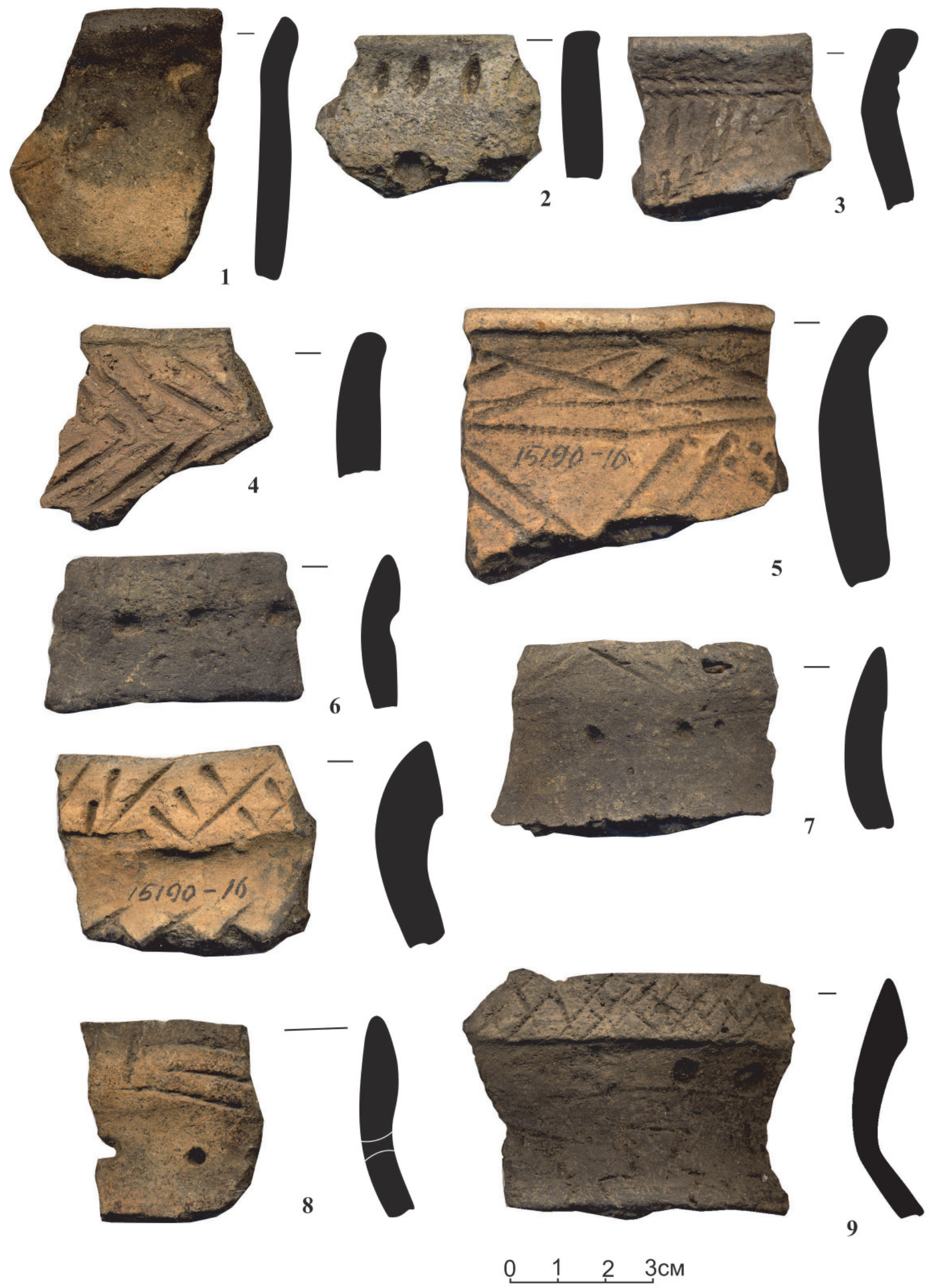

Рис.4 


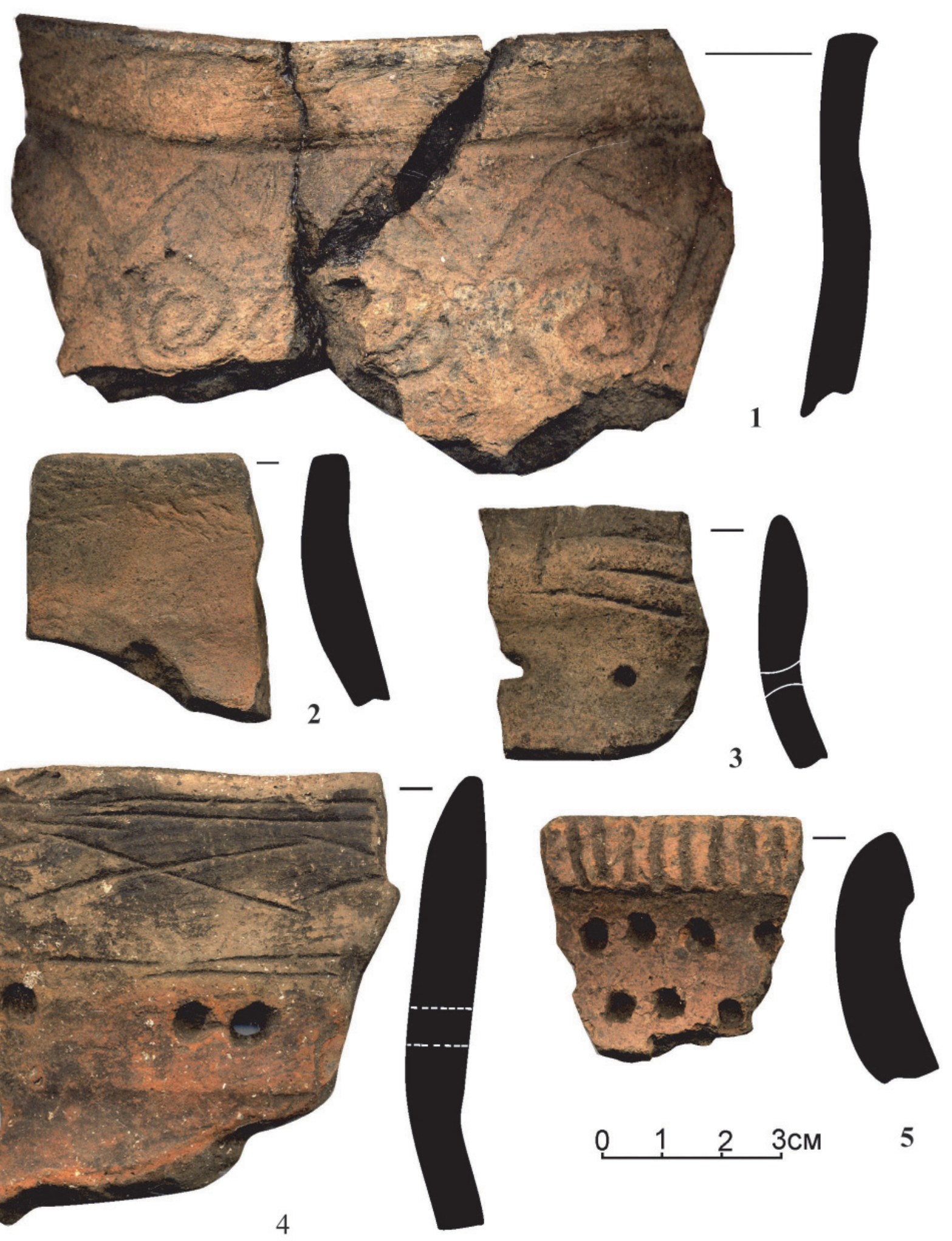

Рис.5 

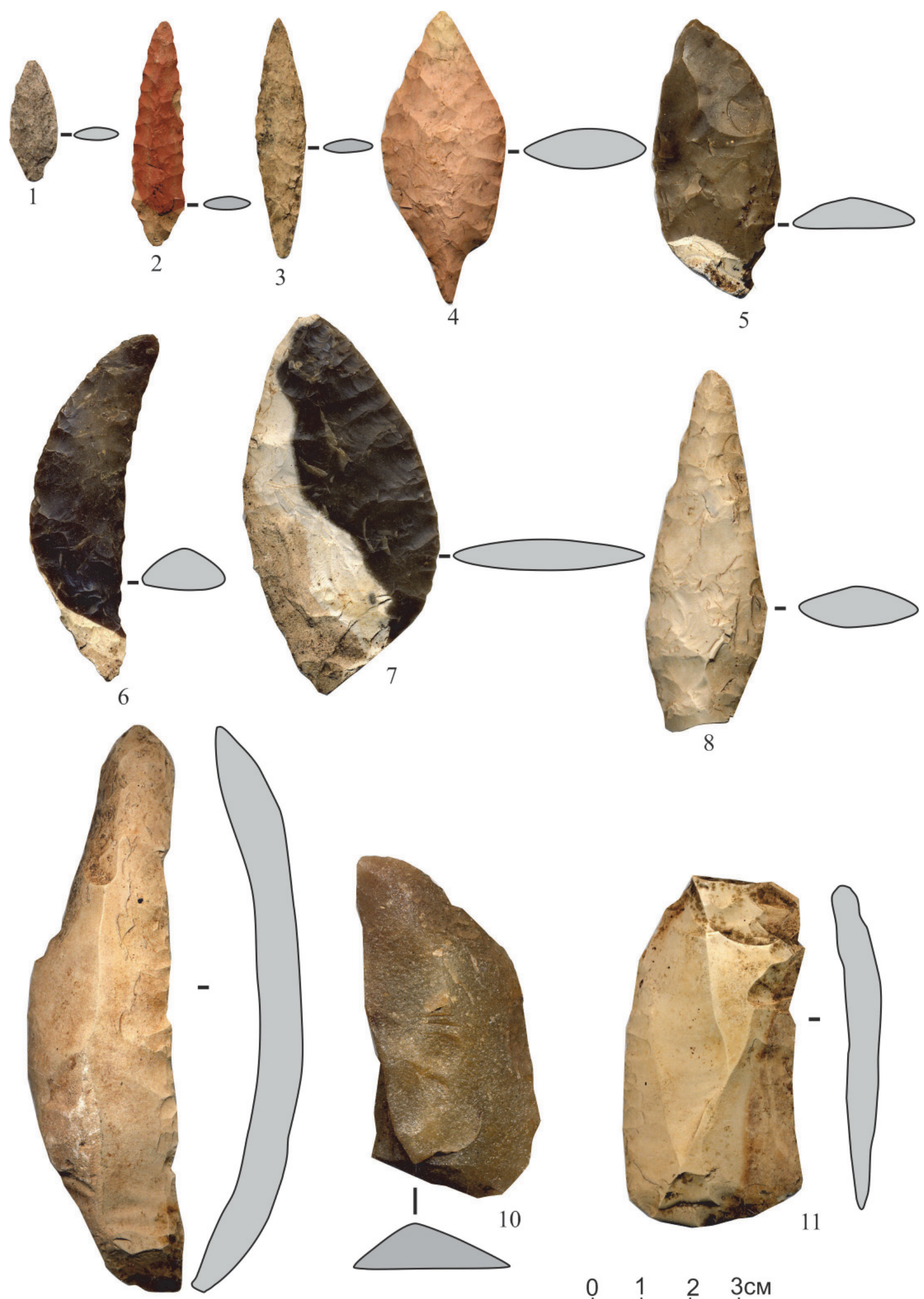

9
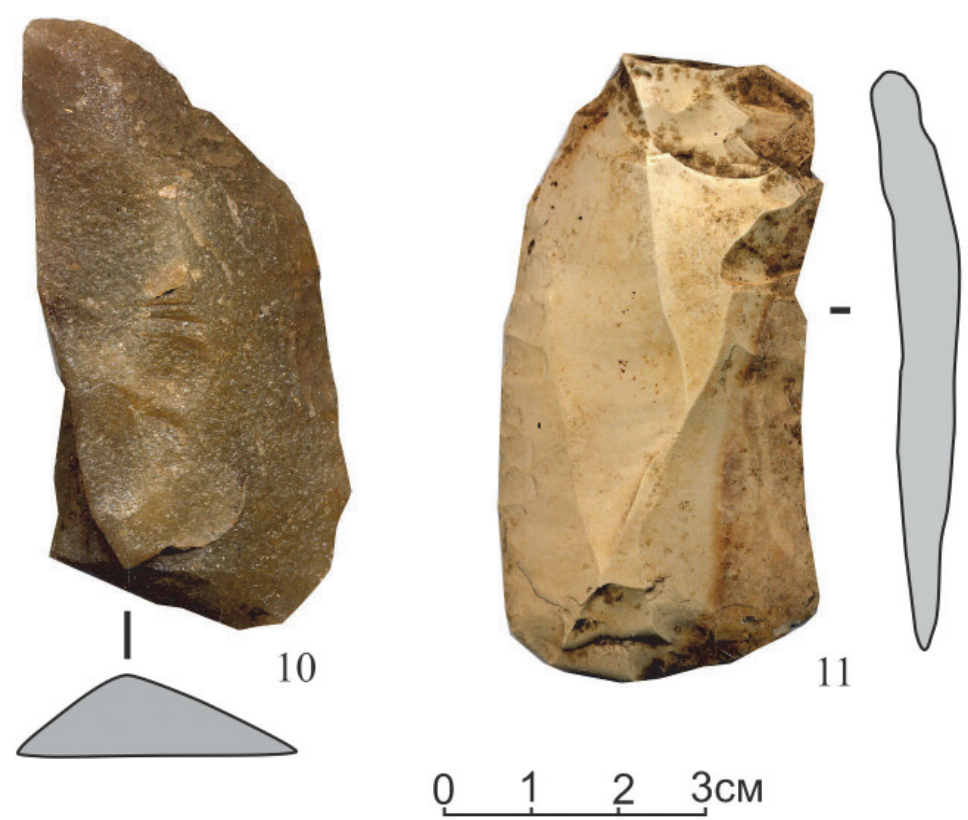

Рис.6 

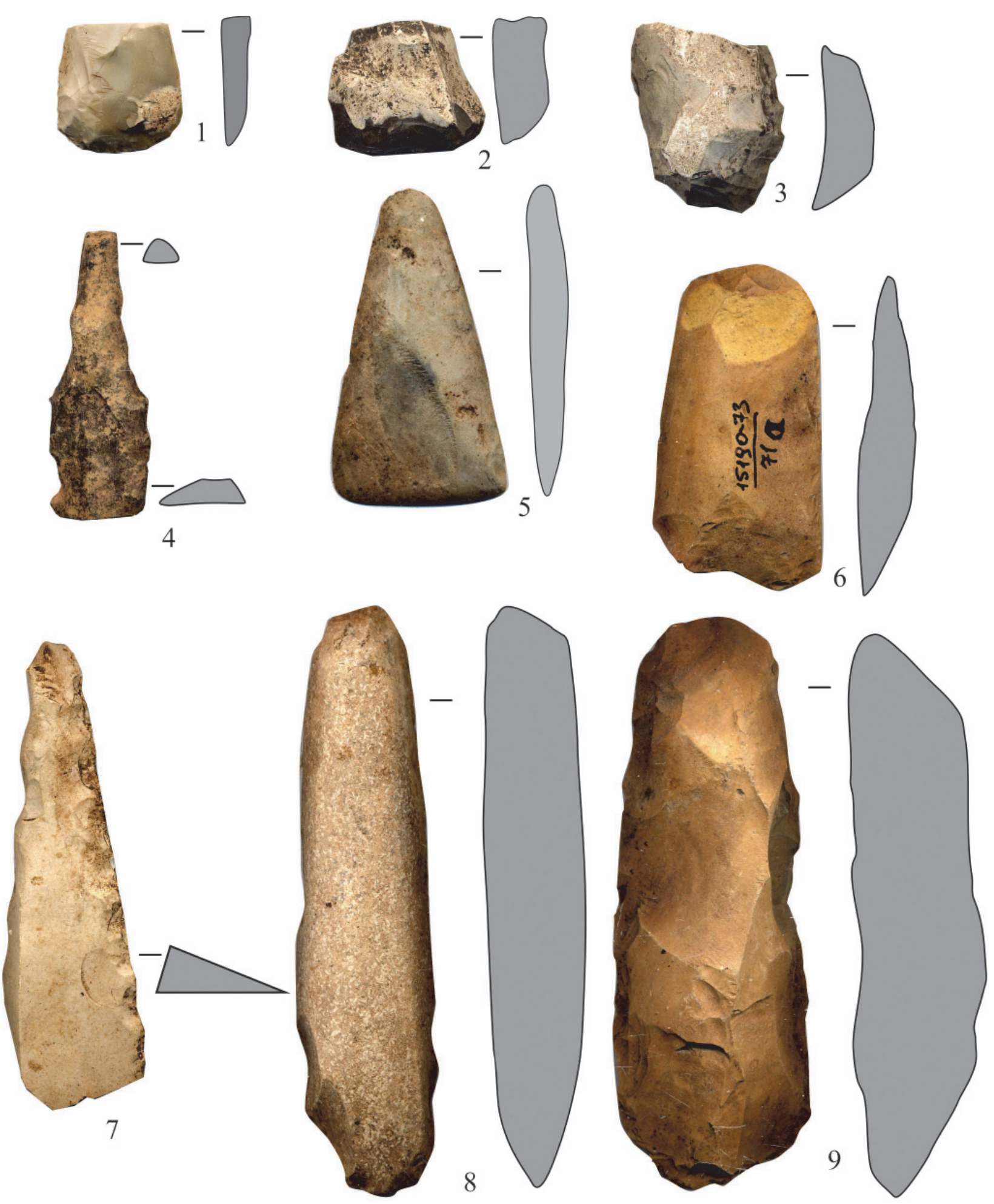

\begin{tabular}{l}
$0 \quad 1 \quad 2 \quad 3 \mathrm{~cm}$ \\
\hline
\end{tabular}

Рис.7 


\title{
Список сокращений:
}

AЕС - Археология Евразийских степей

МИА - Материалы и исследования по археологии СССР

ПА - Поволжская археология

\section{CULTURAL-CHRONOLOGICAL COMPLEXES OF THE SITE OF BERYOZOGRIVSKO-ALEXEEVSKOE III IN THE LOW KAMA REGION}

\author{
(c) 2021 A.V. Shipilov \\ Institute of Archaeology named after A.Kh. Khalikov \\ of the Academy of Sciences of the Republic of Tatarstan, Kazan
}

The article represents the materials of study of the site of Beryozogrivsko-Alexeevskoe III that is situated in the Low Kama region. The earliest findings from this site are associated with Kamskaya Neolithic culture. A somewhat later chronological position is occupied by the complexes represented with the pit-comb, Russko-Azibeyskaya and Novoil'inskaya ceramics. The complex of findings associated with the Garinskaya Eneolithic culture deserves special attention in the article. The largest number of finds belongs to the Bronze Age. They are combined into several complexes belonging to the Srubnaya, Lugovskaya, and Maklasheevskaya cultures. The latest history of the Beryozogrivsko-Alexeevskoe III site was associated with the Anan'inskaya cultural and historical area.

Keywords: ceramics, Neolithic, Eneolithic, Bronze Age, Early Iron Age, Low Kama region.

DOI: 10.37313/2658-4816-2021-3-4-102-114 